\title{
Seroprevalence of SARS-CoV-2 among Health Care Personnel in Portugal ${ }^{\dagger}$
}

\author{
Álvaro de Carvalho ${ }^{1}$, Ana Virgolino ${ }^{2,3, * \mathbb{C}}$, José Germano de Sousa ${ }^{4}\left(\mathbb{D}\right.$, Henrique Barros ${ }^{5}$, Miguel Guimarães ${ }^{6}$ \\ and Francisco Antunes 2,3 (D)
}

1 Fundação Álvaro Carvalho, 1050-125 Lisboa, Portugal; alvaro.e.carvalho@gmail.com

2 Instituto de Saúde Ambiental, Faculdade de Medicina, Universidade de Lisboa, 1649-028 Lisboa, Portugal; fantunes@medicina.ulisboa.pt

3 Laboratório Associado TERRA, Faculdade de Medicina, Universidade de Lisboa, 1640-028 Lisboa, Portugal

4 Germano de Sousa Group, Centro de Medicina Laboratorial, Pólo Tecnológico de Lisboa, 1600-513 Lisboa, Portugal; germanosousa@cm-lab.com

5 EPIUnit-Instituto de Saúde Pública, Universidade do Porto, 4050-091 Porto, Portugal; hbarros@med.up.pt

6 Ordem dos Médicos Portugueses, 1749-084 Lisboa, Portugal; mgdeep@gmail.com

* Correspondence: avirgolino@medicina.ulisboa.pt; Tel.: +351-21-799-9489

+ Presented at the 3rd International Electronic Conference on Environmental Research and Public Health-Public Health Issues in the Context of the COVID-19 Pandemic, 11-25 January 2021; Available online: https:/ / ecerph-3.sciforum.net/.

check for updates

Citation: de Carvalho, Á.; Virgolino, A.; de Sousa, J.G.; Barros, H.; Guimarães, M.; Antunes, F. Seroprevalence of SARS-CoV-2 among Health Care Personnel in Portugal. Med. Sci. Forum 2021, 4, 24. https://doi.org/10.3390/ECERPH-309068

Academic Editor: Zahid Ahmad Butt

Published: 1 January 2021

Publisher's Note: MDPI stays neutral with regard to jurisdictional claims in published maps and institutional affiliations.

Copyright: (c) 2021 by the authors. Licensee MDPI, Basel, Switzerland. This article is an open access article distributed under the terms and conditions of the Creative Commons Attribution (CC BY) license (https:/ / creativecommons.org/licenses/by/ $4.0 /)$.

\begin{abstract}
Health care personnel (HCP) might be highly exposed to SARS-CoV-2 infection. This study aims to determine the seroprevalence of SARS-CoV-2 among HCP in Portugal. A cross-sectional study was conducted between 1 June and 19 July 2020, following the first wave of COVID-19 in the country, with a convenience sample of HCP from different Portuguese health care units, geographically distributed at the national level. Diagnosis of COVID-19 was an exclusion criterion. HCP were tested for IgG antibodies against SARS-CoV-2. Data regarding participants' demographic characteristics, medical history, COVID-19 symptoms, previous clinical testing for acute SARS-CoV-2 infection and Personal Protective Equipment (PPE) practices while caring for patients in areas with COVID19 patients were also recorded. A total of $1802 \mathrm{HCP}$ were screened (80.9\% women), of which 55 $(3.1 \%)$ had positive test results for SARS-CoV-2 antibodies. Factors such as geographical distribution $(p=0.002)$, profession $(p=0.018)$, having had a family member with COVID-19 $(p<0.001)$ and having had contact with family members with COVID-19 $(p=0.003)$ were found to be associated with infection. Adjusting for gender, age group, regional health administration and size of the household, health care assistants have an increased risk of having a positive SARS-CoV-2 test result in comparison to nurses. Understanding the prevalence of and factors associated with SARS-CoV-2 infection among $\mathrm{HCP}$ is important for developing effective strategies to protect them and their patients.
\end{abstract}

Keywords: COVID-19; SARS-CoV-2 seroprevalence; first wave; health care personnel; health administrative regions; Portugal

\section{Introduction}

COVID-19, the disease caused by the severe acute respiratory syndrome coronavirus 2 (SARS-CoV-2), has already caused more than one million deaths worldwide, with more than eighty-two million confirmed cases, and counting, according to recent data from the World Health Organization [1]. On the frontline in combatting against the disease, due to close contact with patients with COVID-19 or insufficient access to Personal Protective Equipment (PPE), health care personnel (HCP) are at high risk for contracting SARS-CoV$2[2-5]$.

Of the European countries, Italy and Spain were the first and most severely hit by COVID-19, with limited time to prepare the health care sector and to take precautions to 
reduce the spread of the infection to HCP [6,7]. In other countries, like Denmark, with more time for preparation, the prevalence of HCP with antibodies against SARS-CoV-2 was low [2]. In Portugal, there is a lack of evidence regarding the real situation in the health care setting. There is an absence of studies specifically targeting this population. However, it has been pointed out that there is a large percentage of asymptomatic cases which may account for up to four-fifths of all SARS-CoV-2 cases [8].

In this context, the surveillance of the proportion of seropositive HCP is important to monitor the spread of the virus [2]. Moreover, understanding the prevalence of and factors associated with SARS-CoV-2 infection among HCP are important for developing effective strategies to protect them and their patients [9].

This study aims to characterize the seroprevalence of SARS-CoV-2 among HCP in Portugal and to identify potential factors associated with the infection in this population.

\section{Methods}

A cross-sectional study was conducted between 1 June and 19 July 2020, following the first wave of COVID-19 in the country. A convenience sample of HCP working in different Portuguese health units, both from the community and clinical settings, geographically distributed at the national level (mainland Portugal) was included. Participants were recruited in hospital based-units, primary health care centers, nursing homes, long-term care facilities and public health units. Inclusion criteria were HCP (nurses, doctors, health care assistants and technicians) working in one of the recruiting sites who considered themselves to have had any contact with patients in relation to their work. Diagnosis of COVID-19 was an exclusion criterion of the study.

Participants were tested for antibodies to SARS-CoV-2 with a chemiluminescence immunoassay that detect and quantify SARS-CoV-2 antibodies anti-IgG. Information on demographic characteristics, medical history, COVID-19 symptoms, previous clinical testing for acute SARS-CoV-2 infection and PPE practices while caring for patients in areas with COVID-19 patients were also obtained from the participants.

Descriptive statistics were used to report the relative and absolute frequencies of each categorical variable and mean and standard deviation were used for continuous variables. Bivariable analyses were performed using chi-square and Fisher exact tests for categorical variables and the $t$-test test (or the equivalent non-parametric Mann-Whitney test) for numeric variables. The association between SARS-CoV-2 seropositivity (primary outcome) and profession was studied through logistic regression modeling. Crude and adjusted odds ratios (OR) with a 95\% confidence interval were calculated; the model was adjusted for gender, age group, health administrative regions and size of the household. Statistical analyses were performed with IBM SPSS ${ }^{\circledR}$ Statistics for Windows (version 25.0) (IBM Corp., Armonk, NY, USA). Results were based on two-sided tests and statistical significance was considered when $p$-value $<0.05$.

The study followed the Declaration of Helsinki principles [10]. The study was approved by the National Ethical and Deontological Committee of the Portuguese Medical Association (Conselho Nacional de Ética e Deontologia da Ordem dos Médicos). Only HCP who agreed to participate and gave oral informed consent took part in the study.

\section{Results}

A total of $1802 \mathrm{HCP}$ participated in the study. Among all participants, $55(3.1 \%)$ had positive test results for SARS-CoV-2 antibodies.

Table 1 provides a characterization of the sample (i.e., individuals who had a negative versus individuals with a positive test result for the SARS-CoV-2 serological test) for main sociodemographic variables. In total, $80.9 \%$ of the participants were women; no differences were found between groups regarding gender. The sample included HCP from all health administrative regions of mainland Portugal; a higher proportion of individuals with a negative serologic SARS-CoV-2 test in all considered regions was observed. Almost half of the participants $(48.1 \%)$ were nurses and $29.6 \%$ were doctors. 
Table 1. Sociodemographic characteristics of the participants by SARS-CoV-2 serology results $(n=1802)$.

\begin{tabular}{|c|c|c|c|c|}
\hline & \multirow{2}{*}{ No. } & IgG $-(<15 \mathrm{U} / \mathrm{mL})$ & $\mathrm{IgG}+(\geq 15 \mathrm{U} / \mathrm{mL})$ & \multirow{2}{*}{$p$-Value } \\
\hline & & No. $(\%)$ & No. $(\%)$ & \\
\hline \multicolumn{5}{|l|}{ Gender } \\
\hline Female & 1459 & $1412(96.8)$ & $47(3.2)$ & 0.492 \\
\hline Male & 343 & $335(97.7)$ & $8(2.3)$ & \\
\hline \multicolumn{5}{|l|}{ Health administrative region } \\
\hline South (Alentejo/Algarve) & 173 & $167(96.5)$ & $6(3.5)$ & \\
\hline Center & 219 & $209(95.4)$ & $10(4.6)$ & 0.002 \\
\hline Lisbon and Tagus Valley & 1135 & $1112(98.0)$ & $23(2.0)$ & \\
\hline North & 258 & $242(93.8)$ & $16(6.2)$ & \\
\hline \multicolumn{5}{|l|}{ Profession } \\
\hline Healthcare Assistants & 175 & $164(93.7)$ & $11(6.3)$ & \\
\hline Nurse & 867 & 847 (97.7) & $20(2.3)$ & \\
\hline Doctor & 534 & $517(96.8)$ & $17(3.2)$ & 0.018 \\
\hline Technician & 117 & $116(99.1)$ & $1(0.9)$ & \\
\hline Other $^{\mathrm{a}}$ & 109 & $103(94.5)$ & $6(5.5)$ & \\
\hline
\end{tabular}

a The 'other' group refers to general services employers.

From the participating HCP, 55 (3.6\%) reported having had a person in the family with COVID-19; a difference between the two groups under analysis was observed. Likewise, 51 of the participants $(4.1 \%)$ had contact with family members with COVID-1; within this sub-group, though, $11.8 \%$ had a positive test result for SARS-CoV-2. Although not statistically significant, the majority of the HCP who indicated always using PPE had a SARS-CoV-2 negative test $(96.8 \%)$ and only $3.2 \%$ were found to be infected by the virus (Table 2).

Table 2. Previous symptoms of COVID-19, testing for acute SARS-CoV-2 infection and use of PPE by SARS-CoV-2 serology results $(n=1802)$.

\begin{tabular}{|c|c|c|c|c|}
\hline & \multirow{2}{*}{ No. } & $\mathrm{IgG}-(<15 \mathrm{U} / \mathrm{mL})$ & $\mathrm{IgG}+(\geq 15 \mathrm{U} / \mathrm{mL})$ & \multirow{2}{*}{$p$-Value } \\
\hline & & No. (\%) & No. (\%) & \\
\hline \multicolumn{5}{|c|}{ Family member with COVID-19 } \\
\hline No & 1488 & 1447 (97.2) & $41(2.8)$ & $<0.001$ \\
\hline Yes & 55 & $46(83.6)$ & $9(16.4)$ & \\
\hline \multicolumn{5}{|c|}{$\begin{array}{l}\text { Contact with family members } \\
\text { with COVID-19 }\end{array}$} \\
\hline $\mathrm{No}$ & 1197 & $1160(96.9)$ & $37(3.1)$ & 0.003 \\
\hline Yes & 51 & $45(88.2)$ & $6(11.8)$ & \\
\hline \multicolumn{5}{|l|}{ Use of PPE } \\
\hline Sometimes/Never & 333 & 325 (97.6) & $8(2.4)$ & 0.547 \\
\hline Always & 1461 & $1414(96.8)$ & $47(3.2)$ & \\
\hline
\end{tabular}

Results of logistic regression assessing profession as a predictor of SARS-CoV-2 serology are provided in Table 3. Adjusting for gender, age group, health administrative region and size of the household, health care assistants have a 3.08 odds ratio of having a positive SARS-CoV-2 test result in comparison to nurses. 
Table 3. Assessing profession as predictor of SARS-CoV-2 serology result $(n=1802)$.

\begin{tabular}{ccc}
\hline & Non-Adjusted OR (CI 95\%) & Adjusted OR (CI 95\%) \\
\hline Nurse & 1 & 1 \\
Health care assistants & $2.84(1.29,5.94)$ & $3.08(1.38,6.58)$ \\
Doctor & $1.39(0.71,2.68)$ & $1.68(0.85,3.30)$ \\
Technician & $0.37(0.02,1.78)$ & $0.31(0.02,1.53)$ \\
Other $^{\text {a }}$ & $2.47(0.89,5.94)$ & $2.53(0.88,6.38)$ \\
\hline
\end{tabular}

a The 'other' group refers to general services employers.

\section{Discussion}

This was the first study in Portugal targeting HCP which aimed to determine the seroprevalence of SARS-CoV-2 and factors associated with the infection in this population. A prevalence of $3.1 \%$ of SARS-CoV-2 infection among HCP was found, a lower rate than what has been estimated by the Portuguese health authorities for this group [11] and what has been reported for the general public [12]. This, however, can be worrisome as the infection might be unrecognized because without regular testing many HCP working in the forefront can have only mild symptoms of SARS-CoV-2 infection or be asymptomatic [9].

Another relevant finding was the increased risk of infection found both in the health care assistants and in the other group (though a result not statistically significant in the latest). In fact, health workers can acquire COVID-19 infection in the community and in the workplace. The risk of infection in the community depends on housing conditions. Operational assistants and general services employers are at the base of the health care workers' socioeconomic pyramid. A significant number of them are migrants and share small housing spaces with people from different families and different ages, including school aged children. At the workplace, the operational assistants are in direct contact with the patients and with the patients' environment, such as eating utensils and contaminated lines. On the other hand, they lack familiarity with PPE, or the time required for the infection prevention and control (IPC) policies. Doctors and nurses are already familiar with IPC and mandatory comprehensive SARS-CoV-2 related PPE training [13].

Against this background, frequent testing of $\mathrm{HCP}$ is pivotal in order to monitor the spread of the virus [2]. Moreover, although our results did not enable us to find a positive association, the provision of PPE in health care settings is an important measure that can contribute to the reduction of the transmission of SARS-CoV-2. Additional protection measures include frequent hand hygiene (before and after using PPE, and when in contact with potentially contaminated objects with respiratory secretions), regular disinfection of surfaces, especially those with which patients were in contact and ventilate the work rooms [14].

Our study also showed that contacts outside work, for example, with household contacts, can also be a source of SARS-CoV-2 infection. In the future, more information about these contacts and what the impact is on the self, namely, if the professional developed COVID-19 symptoms and adopted measures as a result.

\section{Conclusions}

Understanding the prevalence of SARS-CoV-2 infection among HCP and which professional groups have an increased risk of being infected is important to develop effective strategies to protect them and the patients with whom they are in close contact.

Author Contributions: Conceptualization, Á.d.C., J.G.d.S., M.G. and F.A.; methodology, Á.d.C., J.G.d.S. and F.A.; data collection, J.G.d.S.; writing-original draft preparation, A.V. and F.A.; writingreview and editing, Á.d.C., A.V., J.G.d.S., H.B., M.G. and F.A. All authors have read and agreed to the published version of the manuscript.

Funding: This research was funded by Fundação Álvaro de Carvalho, Fundação Vox Populi, Fundação Manuel Viegas Guerreiro and the Claude and Sofia Foundation. 
Institutional Review Board Statement: The study was conducted according to the guidelines of the Declaration of Helsinki, and approved by the National Ethical and Deontological Committee of the Portuguese Medical Association.

Informed Consent Statement: Informed consent was obtained from all subjects involved in the study.

Data Availability Statement: The data presented in this study are available on request from the corresponding author. The data are not publicly available due to privacy reasons.

Acknowledgments: The authors would like to thank the health care workers that accepted to participate in this serosurvey, the technicians of the Centro de Medicina Laboratorial Germano de Sousa that collected the samples and P.Q. of Fundação Vox Populi for the technical support.

Conflicts of Interest: The authors declare no conflict of interest.

\section{References}

1. World Health Organization. Coronavirus Disease (COVID-19) Pandemic. Available online: https://covid19.who.int/ (accessed on 3 January 2021).

2. Iversen, K.; Bundgaard, H.; Hasselbalch, R.B.; Kristensen, J.H.; Nielsen, P.B.; Pries-Heje, M.; Knudsen, A.D.; Christensen, C.E.; Fogh, K.; Norsk, J.B.; et al. Risk of COVID-19 in health-care workers in Denmark: An observational cohort study. Lancet Infect. Dis. 2020, 20, 1401-1408. [CrossRef]

3. Mutambudzi, M.; Niedzwiedz, C.; Macdonald, E.; Leyland, A.; Mair, F.; Anderson, J.; Celis-Morales, C.; Cleland, J.; Forbes, J.; Gill, J.M.; et al. Occupation and risk of severe COVID-19: Prospective cohort study of 120,075 UK Biobank participants. Occup. Environ. Med. 2020, 78, 307-314. [CrossRef] [PubMed]

4. Calò, F.; Russo, A.; Camaioni, C.; De Pascalis, S.; Coppola, N. Burden, risk assessment, surveillance and management of SARS-CoV-2 infection in health workers: A scoping review. Infect. Dis. Poverty 2020, 9, 139. [CrossRef] [PubMed]

5. Wang, X.; Zhang, X.; He, J. Challenges to the system of reserve medical supplies for public health emergencies: Reflections on the outbreak of the severe acute respiratory syndrome coronavirus 2 (SARS-CoV-2) epidemic in China. Biosci. Trends 2020, 14, 3-8. [CrossRef] [PubMed]

6. Centro Nacional de Epidemiologia-Instituto de Salud Carlos III COVID-19 en España. Available online: https:/ / cnecovid.isciii. es/covid19/ (accessed on 4 January 2021).

7. Remuzzi, A.; Remuzzi, G. COVID-19 and Italy: What next? Lancet 2020, 395, 1225-1228. [CrossRef]

8. Day, M. Covid-19: Four fifths of cases are asymptomatic, China figures indicate. BMJ 2020, 369, m1375. [CrossRef] [PubMed]

9. Self, W.H.; Tenforde, M.W.; Stubblefield, W.B.; Feldstein, L.R.; Steingrub, J.S.; Shapiro, N.I.; Ginde, A.A.; Prekker, M.E.; Brown, S.M.; Peltan, I.D.; et al. Seroprevalence of SARS-CoV-2 among Frontline Health Care Personnel in a Multistate Hospital Network-13 Academic Medical Centers, April-June 2020. MMWR Morb. Mortal. Wkly. Rep. 2020, 69, 1221-1226. [CrossRef] [PubMed]

10. World Medical Association. WMA Declaration of Helsinki-Ethical Principles for Medical Research Involving Human Subjects; World Medical Association: Fortaleza, Brazil, 2013.

11. Madeira, J. Press Conference of the Portuguese Council of Ministers, 8 September 2020. Available online: https: / / www.portugal.gov.pt/pt/gc22/comunicacao/multimedia?m=v\&i=conferencia-de-imprensa-do-conselho-de-ministros-de8-de-outubro-de-2020 (accessed on 4 January 2021).

12. Direção-Geral da Saúde COVID-19. Available online: https:/ / covid19.min-saude.pt/ (accessed on 4 January 2021).

13. Mdzinwa, N.; Voigt, M.; Van Rensburg, C.J.; Paruk, F. SARS-CoV-2 infection prevalence in healthcare workers and administrative and support staff: The first-wave experience at three academic hospitals in the Tshwane district of Gauteng Province, South Africa. S. Afr. Med. J. 2021, 111, 1092-1097. [CrossRef]

14. World Health Organization. Infection Prevention and Control during Health Care When Coronavirus Disease (COVID-19) Is Suspected or Confirmed 2021. Available online: https:/ / www.who.int/publications/i/item/WHO-2019-nCoV-IPC-2021.1 (accessed on 4 January 2021). 